\title{
CHALLENGES IN STUB HOLE OPTIMISATION OF CAST IRON RODDED ANODES
}

\author{
Daniel Richard ${ }^{l}$, Patrice Goulet ${ }^{2}$, Olivier Trempe ${ }^{2}$, Marc Dupuis $^{3}$ and Mario Fafard ${ }^{2}$ \\ ${ }^{1}$ Hatch, 5 Place Ville Marie, Bureau 200, Montréal (Québec), Canada, H3B 2G2 \\ ${ }^{2}$ Aluminium Research Centre - REGAL, Laval University, Science and Engineering Faculty, \\ Adrien-Pouliot Building, Sainte-Foy (Québec), Canada, G1K 7P4 \\ ${ }^{3}$ GéniSim Inc., 3111 rue Alger, Jonquière (Québec), Canada, G7S 2M9
}

Keywords: Numerical Analysis, Contact Resistance, Anode, Stub Hole

\begin{abstract}
Reduction of cell voltage through redesign of the stub holes of cast iron rodded anodes is an attractive idea. In practice, stub hole optimisation is not an easy task and in situ trials may yield what seem to be counter-intuitive results.
\end{abstract}

A closer examination reveals a complex behaviour of the steel stub - cast iron - carbon joint. It was shown in previous work [1] to be a non-linear thermal-electrical-mechanical coupled system. Minimisation of the stub-to-carbon voltage drop is a balancing act between contact surface area and electrical contact resistance.

To gain insights into the merits of different designs, a finite element demonstration model was built using the in-house code FESh++. Alternative configurations were studied. Potential industrial applications are discussed.

\section{Introduction}

Cast iron is typically used to connect the steel stubs of the anode hangers to the carbon anodes used in Hall-Héroult cells. The steel stubs are positioned into specially designed holes in the carbon anode - the stub holes - where molten iron can be cast. The solidified cast iron in the stub hole plays the role of a mechanical, thermal and electrical connection.

In his 1976 paper, Peterson [2] instrumented an anode with 30 voltage probes and 50 thermocouples. Temperature and potential readings were taken during 24 hours while the anode was in operation. Up to $25 \%$ of the anode voltage drop was attributed to the steel-cast iron-carbon connection. Peterson tested a stub hole of a different design in a furnace, which seemed to indicate negligible contact resistance at high temperature [3]. The results of these two studies seem to be quite contradictory. A clear conclusion is however that an interface resistance (contact resistance) at the cast iron to carbon transition increases the anodic voltage drop.

In practice, it was found that the stub hole voltage drop varies from design to design. This opens the question of the optimal connector design, for which both voltage drop and anode fabrication aspects must be taken into consideration.

\section{Cast Iron to Carbon Contact Resistance}

The basis for the analysis of electrical contact between rough surfaces has been laid out by Holm [9] and Greenwood \& Williamson [10,11]. In principle, rough surfaces in contact have an effective area of contact smaller than the nominal area. A constriction of the flux lines and a reduced effective area contribute to a localised voltage drop rationalised as an interface resistance.

Based on the experimental work of Sørlie \& Gran [12], Richard et al investigated the intrinsic behaviour of the cast iron to carbon contact [1], from which a pressure and temperature-dependent electrical contact resistance (phenomenological) law was derived [8]. Richard et al [1] has also shown the stub-cast iron-carbon assembly to be an indirectly coupled thermal-electricalmechanical system.

\section{Anode Stub Holes Geometry}

While stub holes machined in baked anodes allow for more design freedom, the shape of moulded stub holes in green anodes is somewhat limited by fabrication constraints.

Given that a green anode is relatively fragile, the flute geometry must prevent dimensional warping or material collapse. If the flutes are angled, this angle must allow for the stub hole inserts to rotate properly during demoulding. The flutes must have a 'conical' shape, i.e. their top must be wider and longer than their bottom. The cylindrically shaped part of the connector must also be 'conical', i.e. its radius must be greater on the top. There must remain enough carbon in between two consecutive flutes while a minimum flute width must also be respected. Retractable mechanisms are also used in some instances to create more complex shapes.

Additional constraints due to casting further bound the possible stub hole shapes. To prevent molten iron to solidify until it has totally filled up the stub hole, the ratio of flute width to length has to be high enough. The mass of cast iron must be small enough to allow a good rodding speed to be maintained while a minimum hole width and volume must be provided to prevent spill over. Classical stub holes are shown in Figure 1.

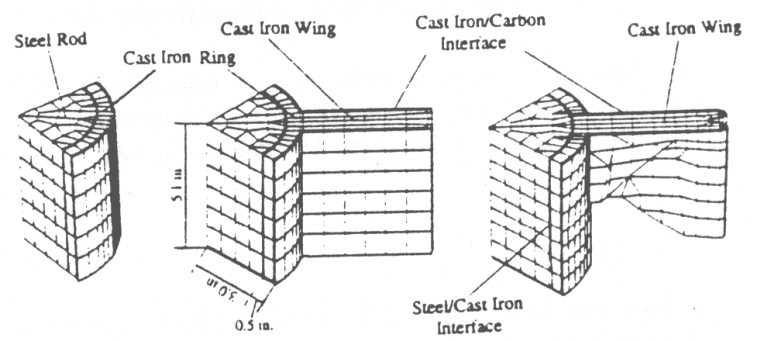

Figure 1 - Classical Stub Holes, reproduced from Hou et al [6] 


\section{Previous Work on Stub Hole Geometry}

Although Brooks \& Bullough [4] and Peterson et al [5] have derived design charts for cylindrical connectors, the influence of flutes and other design features still proved elusive.

Intuitively, adding more surface area by adding flutes or increasing their length should reduce the voltage drop. A trial using such a design ("instrumented anode 2" in [7]) has however yielded a higher voltage drop than the original design ("instrumented anode 1" in [7]).

The numerical investigations of Hou et al (12) did not allow any clear conclusion to be drawn. The limitation of the approach used in the numerical models assumed the contact resistance at the interface constant and independent of pressure or temperature. Also, the cast iron connector was assumed to establish contact with carbon on its entire surface, which in reality might not be the case. Furthermore, no experimental results were presented as a validation to the models assumptions and results.

\section{Air Gap}

It is well known that cast iron does not wet carbon and that once cooled, an air gap opens up between the carbon and cast iron surfaces. The magnitude of the air gap depends notably on the molten iron temperature at pouring, on the carbon and steel stub temperature when the cast iron solidifies, on the cast iron composition and on the cast iron thickness. Usually, the thicker the cast iron, the larger the air gap.

Once set in a pot, the anode heats up and cast iron to carbon contact is established. However, at normal operating temperatures, the thermal expansion of the stubs and cast iron may not be sufficient to generate enough contact pressure for a good contact on the entire interface.

\section{Cast iron to Carbon Contact}

The electrical constitutive law in [8] was then used by Richard et al to evaluate different stub hole designs using a fully coupled thermal-electrical-mechanical model based on the Finite Element Analysis commercial code ANSYS [7]. From preliminary simulations using a pie-shaped section of the steel stub-cast ironcarbon assembly, the three main factors affecting fluted connector performance were found to be the following:

Area of contact Since the air gap increases with cast iron thickness, cast iron might not make contact with carbon on its entire surface. This is especially true for long flutes.

Contact Contact resistance increases with resistance decreasing contact pressure, therefore the further away from the steel stub the contact occurs, the higher the contact resistance.

Mean effective Cast iron being roughly an order of radius magnitude more conductive than carbon, the further away from the steel stub the contact occurs, the shorter the current path in carbon.
In other words, the quality of contact decreases with the distance from the stubs. Traditional ways of increasing (apparent) surface area in fluted designs, like adding flutes, increasing their length or their width, result in a larger mean diameter and a larger mean contact resistance. Minimisation of the stub-to-carbon voltage drop is therefore a balancing act between the real contact area and the resulting electrical contact resistance.

Limitations in the contact mechanics algorithms used by Richard $[1,7,8]$ however limited the accuracy of the results and severely constrained the meshing requirements.

\section{Multiphysics Contact}

Surface-to-surface multiphysics contact, including the effects of thermal contact conductance, electrical contact resistance and Joule heat generation at the interface, was developed and implemented by Goulet [13] in the in-house finite element toolbox $\boldsymbol{F E S h + + ~ [ 1 4 ] ~ u s i n g ~ m o d e r n ~ O b j e c t - O r i e n t e d ~ t e c h n i q u e s . ~ T h e ~ u s e ~}$ of algebraic equations to specify the material properties allows the direct implementation of the electrical contact resistance equations derived by Richard et al [8].

\section{Finite Element Model}

Geometry

Using the same approach than Fortin et al [16], a simplified parametric anode geometry, shown in Figure 2, was developed and meshed with linear hexahedral elements. The geometry includes the part of the aluminium stem, the steel yoke and stubs, cast iron and carbon anode. For the sake of simplicity, the stub hole vertical tapers were neglected. Geometric air gaps at the cast iron / carbon interface are considered.

a) Simplified Anode Assembly

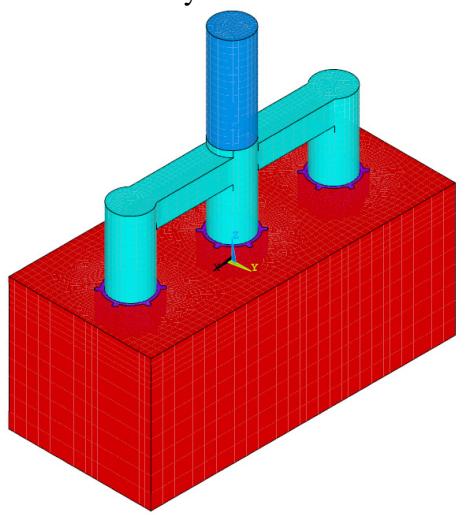

b) Stub to Carbon Detail

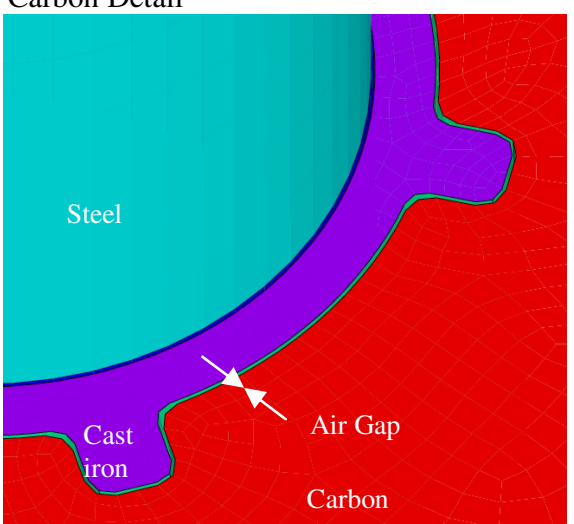

Figure 2- 6 Flutes Base Case Finite Element Model Geometry 


\section{Air Gap Prediction}

The width of the cast iron to carbon air gap depends on the cast iron thickness such that different gaps are considered on the cylindrical sections and at the end of the flutes. A simplified analytical method was used to estimate the magnitude of air gap for moderate changes of stub hole geometry.

With $\gamma$ the change of radius of the steel stub at cast iron solidification, $T_{a}$ the effective stub temperature at cast iron solidification, $T_{0}$ the ambient temperature, radius $_{s t u b}$ the stub radius, $\alpha$ the secant thermal expansion coefficients, $t$ the cast iron thickness and $T_{s}$ the cast iron solidification temperature, the air gap can be estimated by combining equations (1) and (2):

$$
\begin{aligned}
& \gamma=\operatorname{radius}_{\text {stub }} \alpha_{\text {steel }}\left(\mathrm{T}_{\mathrm{a}}-\mathrm{T}_{0}\right) \\
& \text { gap }=\gamma+(\mathrm{t}-\gamma) \alpha_{\text {cast iron }}\left(\mathrm{T}_{\mathrm{s}}-\mathrm{T}_{0}\right)
\end{aligned}
$$

$\underline{\text { Mesh }}$

The Finite Element mesh composition is summarized in Table 1. Multiphysics contact elements are used to establish mechanical contact at the cast iron to carbon interface, determine the contact pressure, and transfer heat and electrical current. A typical mesh for the cast iron is shown in Figure 3.

Table 1 - Finite Element Mesh Composition

\begin{tabular}{|l|c|c|}
\hline \multicolumn{1}{|c|}{ Component } & Element Type & Number \\
\hline Aluminium Stem & Linear Hexahedral & 1856 \\
\hline Steel Stubs and Yoke & Linear Hexahedral & 7196 \\
\hline Cast iron & Linear Hexahedral & 10152 \\
\hline Carbon Anode & Linear Hexahedral & 82257 \\
\hline Stub to Cast iron Interface & Contact Linear Quad & 2718 \\
\hline Cast iron to Carbon Interface & Contact Linear Quad & 6966 \\
\hline
\end{tabular}

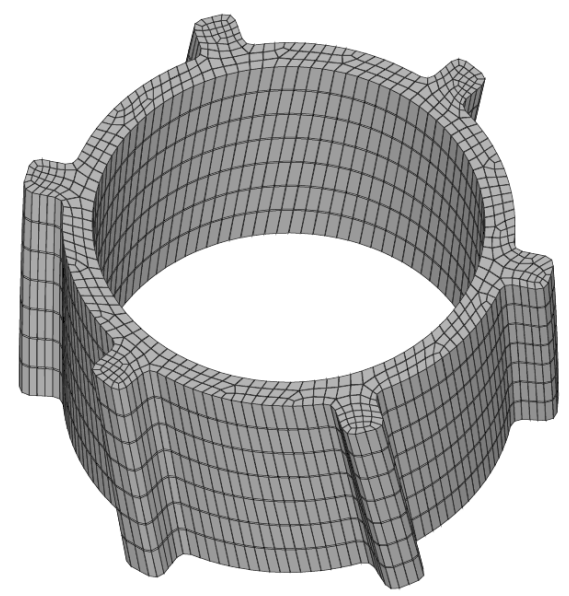

Figure 3 - 6 Flutes Base Case Cast Iron Geometry

\section{Material Properties}

Thermal properties were estimated from Dupuis [17]. For simplicity, all materials were considered elastic. Carbon cracking and crushing in carbon could be taken into account by adapting the constitutive law developed for carbon cathode material by D'Amours et al [15].
Mechanical properties for cast iron and steel were obtained respectively from Katus [18] and Ward [19]. Carbon elastic properties were estimated from Richard $[1,7,8]$.

Cast iron to carbon electrical contact resistance was obtained from [8], using a calibration based on the Brooks \& Bullough data [4]. For the sake of simplicity, given the small changes of contact resistance in the range of temperature in the stub holes at steadystate conditions, the electrical contact resistance $R_{c}$ is assumed to vary only with contact pressure $P[\mathrm{MPa}]$, as defined in equation (3). The resulting electrical contact resistance curve is shown in Figure 4. It is assumed that no contact exist on the stub hole bottom.

$$
\begin{array}{ll}
R_{c}=A-B \exp \left[-(P / C)^{D}\right] & \\
A=35.08954380 & C=0.01532769 \\
B=34.79538085 & D=-1.62109211
\end{array}
$$

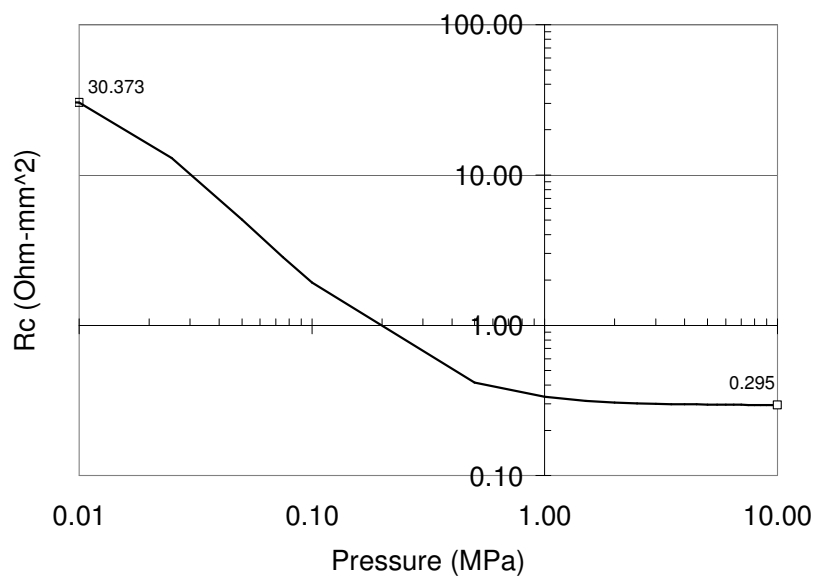

Figure 4 - Assumed Carbon to Cast Iron Electrical Contact Resistance

Boundary Conditions

Similar to Fortin et al [16], equivalent thermal boundary conditions, including partial immersion of the carbon into a $955^{\circ} \mathrm{C}$ bath, were applied through effective convective heat transfer coefficient in order to obtain a reasonable temperature field consistent with Dupuis [17].

The immerged part of the anode was considered to be an equipotential and a current corresponding to an operation at 330 $\mathrm{kA}$ with 40 anodes was forced at the top of the anode yoke assembly.

The bottom of the anode is supported by an equivalent elastic foundation whose stiffness was adjusted to represent the Archimedes force. The top of the anode stem is completely fixed.

Solution Algorithm in FESh++

For efficiency reasons, the problem is split into a fully coupled thermal-electrical sub problem and a mechanical sub problem. The temperature field is transferred to the mechanical sub problem as a body load. Each sub problem is non linear and solved using a classical Newton-Raphson iterative scheme. A successive substitution algorithm iterates between the thermalelectrical and the mechanical sub problems until convergence. 
Previous Work

\section{Discussion}

Previous work from Richard [7] using a pie shaped sub-model (shown in Figure 5) has shown that different designs of stub holes could result in largely different cast iron to carbon voltage drop, as illustrated in Figure 6. In all the simulations, the cylindrical part of the stub hole was kept constant and only the number, width and length of flutes was varied.

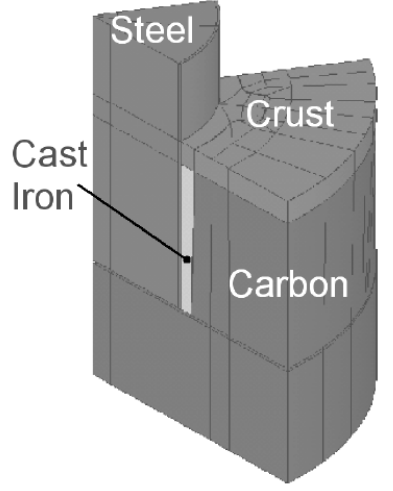

Figure 5 - Pie-shape submodel geometry from Richard [7]

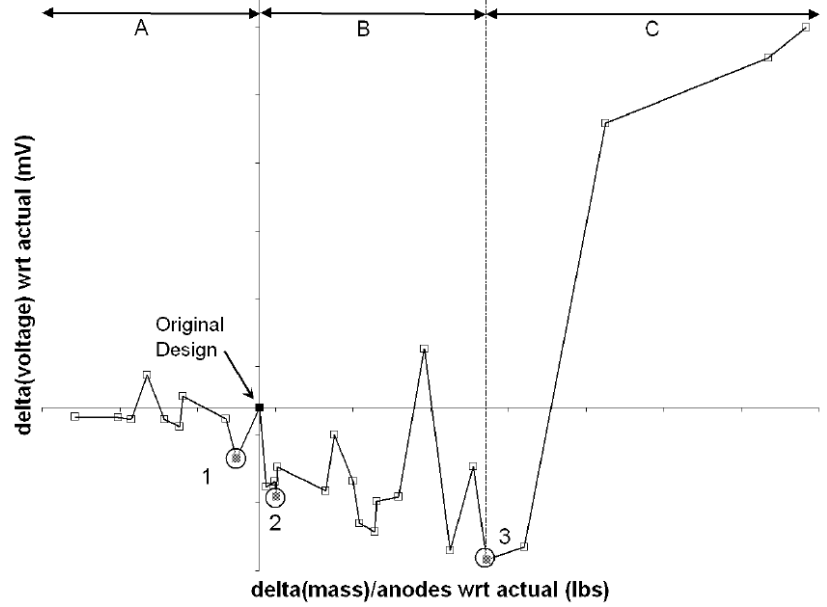

Figure 6 - Variation of voltage drop for different stub hole designs of different cast iron mass, from Richard [7].

It can seen that the original design was difficult to improve upon, but that in Region A, small savings could be achieved with slightly less cast iron (Region A, Point 1), while by adding slightly more cast iron (Region B, Point 2), a more interesting saving could be achieved. A minimum voltage drop was obtained with significantly more cast iron (Point 3 ), which was decreasing the rodding shop productivity to unacceptable levels. In Region C, the contact area achieved at the end of excessively long flutes was severely decreased such that the overall voltage drop was increased.

These simulations were however not considering the effect of the steel yoke expansion and the effect of gravity on the cast iron to carbon contact established.
Typical Results from Full Anode Model Base Case

For the base case shown in Figure 3, gaps of $0.30 \mathrm{~mm}$ at the cylindrical portion of the stub hole and $0.45 \mathrm{~mm}$ at the end of flutes were obtained. Results calculated in FESh++ were postprocessed in ANSYS. A typical temperature distribution is shown in Figure 7. Temperatures in the order of $650^{\circ} \mathrm{C}$ were obtained in the bottom of the stub hole.

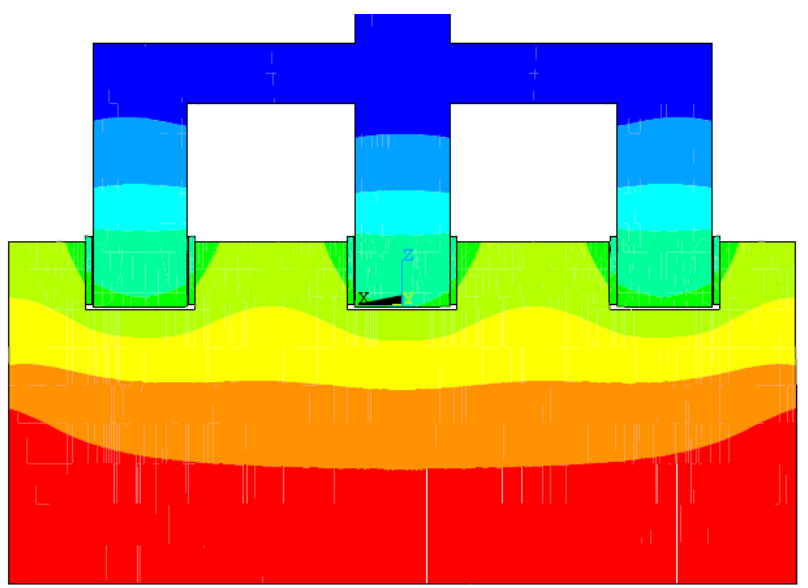

Figure 7 - Base Case Temperature Distribution (increasing from blue to red).

Typical results from the full anode model indicate a higher contact pressure on the cylindrical part of the cast iron, with a moderate pressure on the exterior side of the flute due to gravity, and a lower pressure on the flute tip due to the larger air gap. This is illustrated in Figure 8. As expected, the resulting current density in the carbon, shown in Figure 9, indicates that more current is drawn in the bottom of the stub hole and in the regions of large contact pressure.

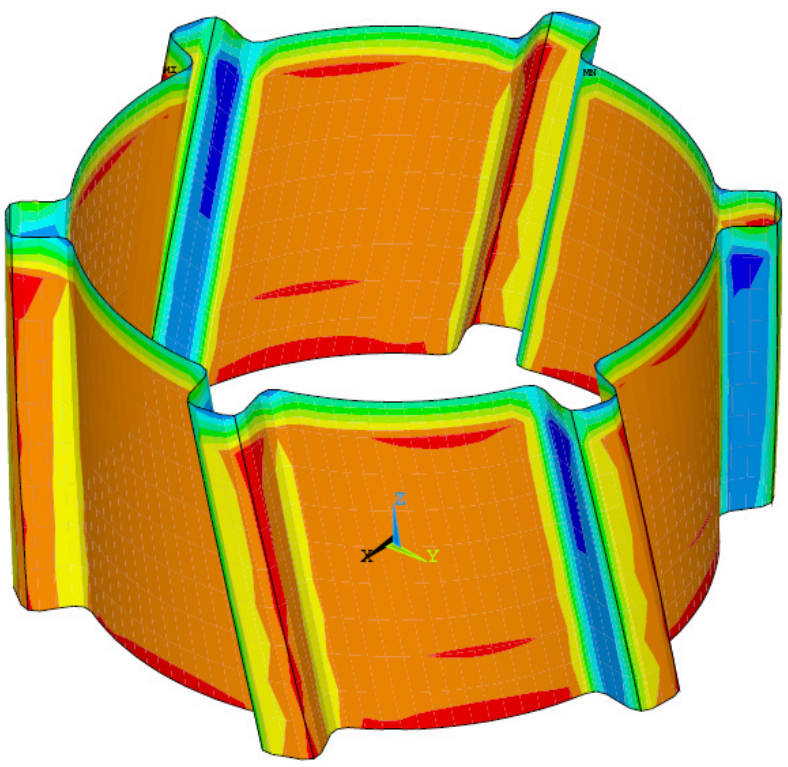

Figure 8 - Base Case Contact Gap at Carbon to Cast Iron Interface (increasing contact intensity from blue to red). 


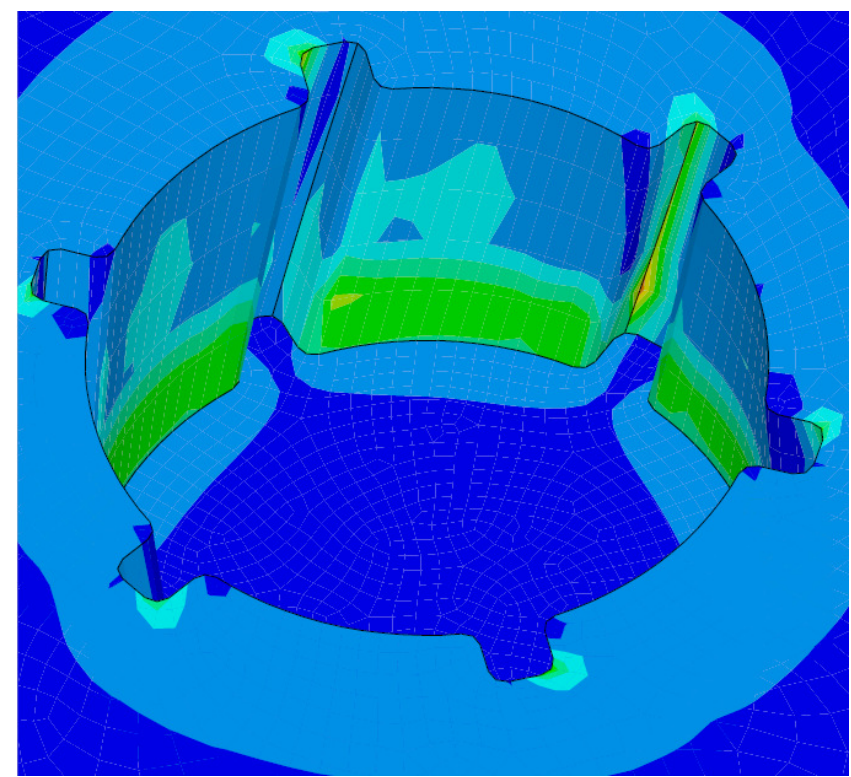

Figure 9 - Base Case Current Density Intensity at Carbon to Cast Iron Interface (increasing from blue to red).

As expected, the resulting predicted voltage across the anode assembly indicates that more current is drawn by the center stub which has a shorter current path to the bath. A typical distribution through the center plane of the assembly is shown in Figure 10. The 6 flutes base case results in a predicted voltage drop in the order of $305 \mathrm{mV}$, and a cast iron to carbon drop in the order of 30 $\mathrm{mV}$.

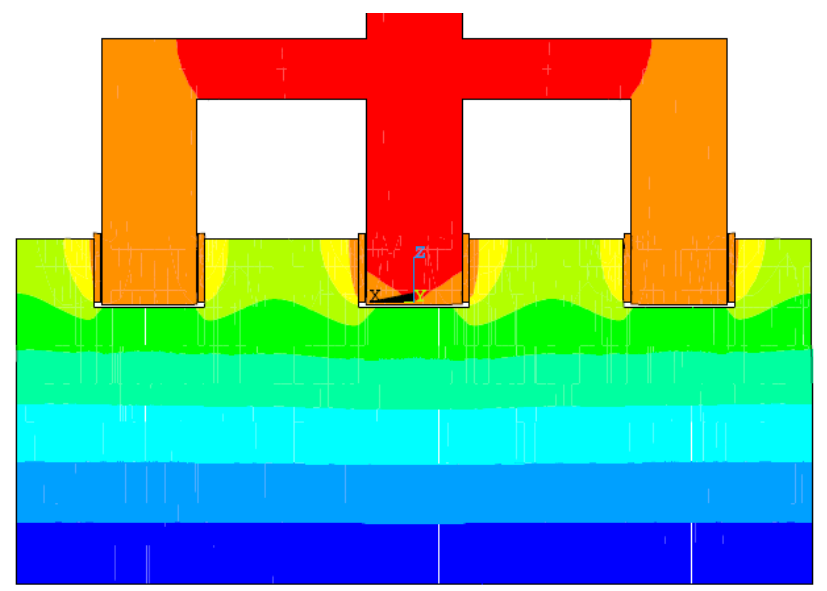

Figure 10 - Base Case Voltage Drop through Center Plane (increasing from blue to red)

\section{Impact of Design}

An intuitive way to reduce the cast iron to carbon voltage drop is to increase the surface area. In reality, the resulting voltage drop will depend on the interaction between contact area and contact quality. To illustrate this, an alternative configuration with a number of flutes increased to 16 was studied. The flutes are identical to the base case, and all other dimensions were kept constant. The finite element mesh is shown in Figure 11.

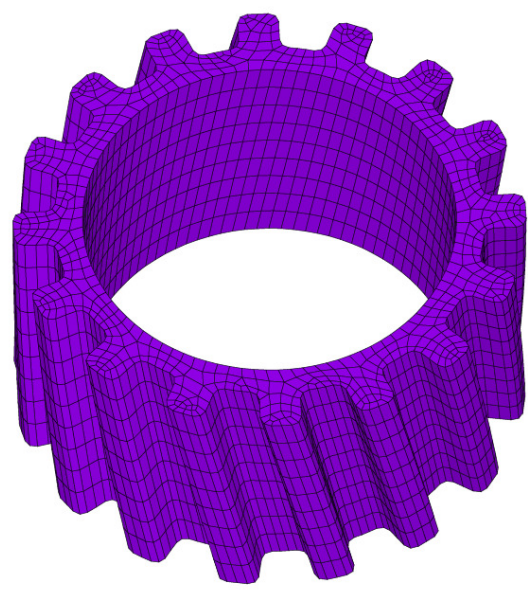

Figure 11 - 16 Flutes Alternative Case Cast Iron Geometry

As expected, the resulting current density in the carbon, shown in Figure 12, reveals a better distribution of current around the circumference of the stub hole. However, the current density is visibly still higher in the bottom portion of the stub hole and in the higher contact pressure zones.

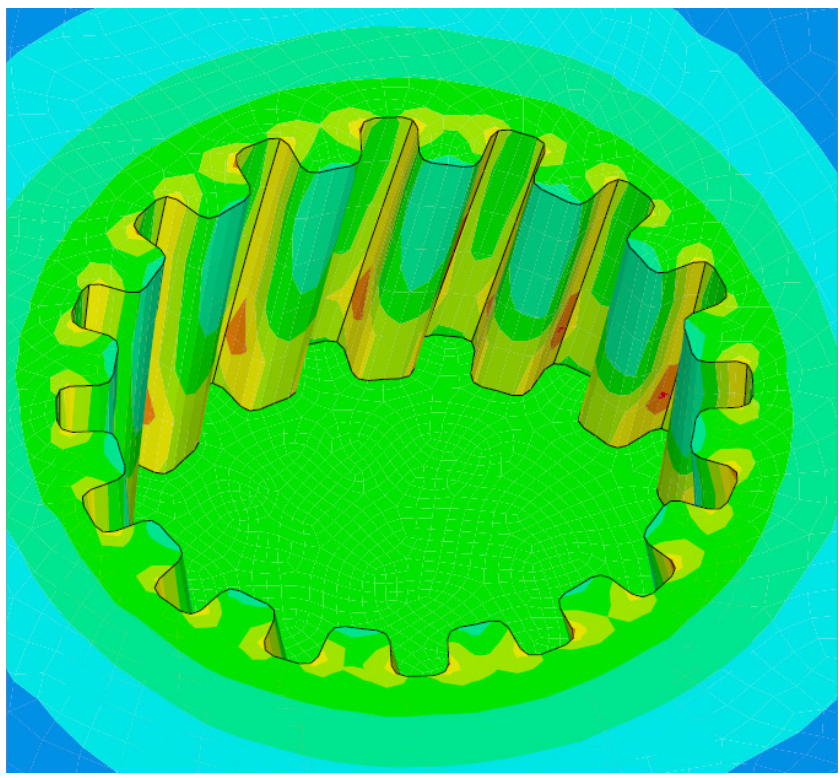

Figure 12 - Alternative Configuration Current Density Intensity at

Carbon to Cast Iron Interface (increasing from blue to red).

The 16 flutes alternative case results in a predicted voltage drop in the order of $307 \mathrm{mV}$.

\section{Discussion}

The comparison between the performance of the 6 flutes and the 16 flutes cases is summarized in Table 2. It can be seen that in the 16 flutes case, the reduction of high quality contact area increased the electrical resistance to the point offsetting the $38.9 \%$ increase in nominal contact area, resulting in a slightly higher anode voltage drop. It is also interesting to note that the 16 flutes configuration requires approximately $37 \%$ more cast iron than the base case, which would lead to a decrease of the rodding shop productivity. 
Table 2 - Summary of Stub Hole Configurations Performance

\begin{tabular}{|c|c|c|c|c|}
\hline \multirow{2}{*}{ CASE } & $\begin{array}{c}\text { Number } \\
\text { of flutes }\end{array}$ & $\begin{array}{c}\text { Cast iron } \\
\text { Mass }\end{array}$ & $\begin{array}{c}\text { Nominal } \\
\text { Contact } \\
\text { Area }\end{array}$ & $\begin{array}{c}\text { Anode } \\
\text { Voltage } \\
\text { Drop }\end{array}$ \\
\cline { 2 - 5 } & {$[-]$} & {$[\mathrm{kg}]$} & {$\left[\mathrm{m}^{2}\right]$} & {$[\mathrm{mV}]$} \\
\hline Base & 6 & 9.78 & 0.110 & 305 \\
\hline Alternative & 16 & 10.50 & 0.154 & 307 \\
\hline
\end{tabular}

In the course of this study, it was found that magnitude of the air gap between cast iron and carbon has a significant impact on the predicted voltage drop, as it controls the resulting contact quality at the carbon to cast iron interface.

\section{Conclusion}

A finite element demonstration model of a simplified anode assembly was built using the in-house code FESh++ to study the impact of the anode stub hole design on the anode voltage drop. The coupled thermal-electrical-mechanical problem was solved iteratively, taking into account the behaviour of the cast iron to carbon cast iron interface.

An alternative 16 flutes stub hole was compared to a base case design with 6 flutes. Despite the increased nominal surface area and the increased cast iron mass, the resulting anode voltage drop was found to increase slightly due to the decrease of contact quality. Minimisation of the stub-to-carbon voltage drop is therefore a balancing act between the real contact area and the resulting electrical contact resistance.

The accurate prediction of the contact quality hinges on the accurate prediction of the ambient temperature air gap between cast iron and carbon. Although it can be calibrated on in situ measurements, development of an analytical or numerical prediction methodology would make an interesting research area.

From the work presented here, it can be seen that a numerical model is an invaluable tool to gain insights into the complex interactions of steel, cast iron and carbon in an anode stub hole. Once validated on experimental measurements, it can be used in the optimisation of the stub hole geometry with respect to anode voltage drop and cast iron volume.

\section{Acknowledgements}

We thank Hugues Fortin from REGAL and Lowy Gunnewiek from Hatch for their support and for the useful discussions and comments. A part of the research presented in this paper was financed by the Fonds québécois de la recherche sur la nature et les technologies by the intermediary of the Aluminium Research Centre - REGAL and Natural Sciences and Engineering Research Council of Canada. We thank also, Daniel Marceau from Aluminium Research Centre - REGAL, for the access to the high performance computing facilities of UQAC.

\section{References}

[1] D. Richard., M. Fafard, R. Lacroix, P. Cléry, \& Y. Maltais, 2000. "Thermo-electro-mechanical modeling of the contact between steel and carbon cylinders using the finite element method'. In Proc. TMS Light Metals, 523-528.
[2] R.W. Peterson, 1976. "Temperature and voltage measurements in Hall cell anodes”, In Proc. TMS Light Metals 1, p. 365-382.

[3] R.W. Peterson, "Studies of stub to carbon voltage", 1978. In Proc. TMS Light Metals 1, p. 367-.378

[4] D.G. Brooks \& V.L Bullough, 1984. "Factors in the design of reduction cell anodes”, In Proc. TMS Light Metals, p. 961-976.

[5] R.W. Peterson, M.D. Ohlswager \& G.E. Goeres, 1989. “Anode cast iron thickness optimization”, In Proc. TMS Light Metals, p. 499-503.

[6] T.X. Hou, Q. Jiao, E. Chin, W. Crowell \& C. Celik, 1995. "A numerical model for improving anode stub design in aluminum smelting process", In Proc. TMS Light Metals, p. 755-761.

[7] D. Richard., M. Fafard, R. Lacroix, P. Cléry, \& Y. Maltais, 2001. "Aluminum reduction cell anode stub hole design using weakly coupled thermo-electro-mechanical finite element models". Finite Elements in Analysis \& Design, 37 (4), 287-304.

[8] D. Richard., M. Fafard, R. Lacroix, P. Cléry, \& Y. Maltais, 2003. "Carbon to cast iron electrical contact resistance constitutive model for finite element analysis". Journal of Material Processing Technology, 132 (1-3), 119-131.

[9] R.Holm, 1967. "Electric Contacts, Theory and Applications" 4th edition, Springer-Verlag, New York

[10] J.A. Greenwood \& J.B.P. Williamson, 1966. "Constriction resistance and the real area of contact", Brit.J.Appl.Phys $\mathbf{1 7}$ (1966), p. 1621-1632.

[11] J.A. Greenwood \& J.B.P. Williamson, 1966. "Contact of nominally flat surfaces", In Proc. Royal Society A295, p. 300319.

[12] M. Sørlie \& H. Gran, 1992. "Cathode collector bar-tocarbon contact resistance", In Proc. TMS Light Metals, 779-787.

[13] P. Goulet, 2004. "Modélisation du comportement thermoélectro-mécanique des interfaces de contact d'une cuve de HallHéroult", Ph.D. Thesis, Université Laval, Québec (Québec), Canada.

[14] M. Désilets, D. Marceau \& M. Fafard, 2003. "START-Cuve: Thermo-electro-mechanical Transient Simulation Applied to Electrical Preheating of a Hall-Héroult Cell', in Proc. TMS Light Metals, 247-254.

[15] G. D’Amours, M. Fafard, A. Gakwaya \& A. Mirchi, 2003. "Multi-Axial Mechanical Behavior of the Carbon Cathode: Understanding, Modeling and Identification", in Proc. TMS Light Metals, 633-639.

[16] H. Fortin, M. Fafard, N. Kandev \& P. Goulet, 2009. "FEM Analysis of the Voltage Drop Induced by the Deterioration of the Anode Stubs", in Proc. TMS Light Metals, To be published.

[17] M. Dupuis, 2000. "Thermo-Electric Design of a $400 \mathrm{kA}$ Cell: A Tutorial", in Proceedings of TMS Light Metals, p. 297-302.

[18] J.R. Katus editor, 1959. Properties of Cast Iron at Elevated Temperatures, ASTM Special Publications, no.448.

[19] S.F. Ward editor, 1955. Elevated-Temperature Properties of Carbon Steel, ASTM Special Publications, no.180. 